\title{
COMMENTS
}

\section{STRUNG OUT: LEGAL CITATION, THE BLUEBOOK, AND THE ANXIETY OF AUTHORITY}

\author{
MICHAEL BACCHUS ${ }^{\dagger}$
}

\section{INTRODUCTION}

At the end of the school year, law schools across the country hold competitions for positions on law journals, and the University of Pennsylvania Law School is no different. Though colloquially known as the "writing competition," Penn Law's competition requires students primarily to rewrite footnotes and citations from an apocryphal law review article to conform to the dictates of The Bluebook. ${ }^{1}$ This may make sense, as the University of Pennsylvania Law Review is one of the four entities (with the Columbia Law Review, the Harvard Law Review, and The Yale Law Journal) that compile The Bluebook, but it is clear that even those schools that have nothing to do with the creation of the "Uniform System of Citation" often rely heavily on the fascinating and frustrating intricacies of The Bluebook's legal citation rules when testing students for placement on the editorial staffs of their legal journals. ${ }^{2}$

${ }^{\dagger}$ B.A. 1989, University of California, Los Angeles; M.A. 1992, University of Southern California; Ph.D. 1997, University of Southern California; J.D. Candidate 2003, University of Pennsylvania. Even the most rococo of constructions could not appropriately reflect the extravagance of gratitude due Professor David A. Skeel for his academic grace in the seminar that inspired this Comment, and his remarkable support outside of it. Thanks also belong to Professor Catherine T. Struve for her intellectual elegance and contagious enthusiasm. No note would be complete without obeisance to four whose profound effect on my academic development cannot be overstated: Professors Joseph A. Boone, James R. Kincaid, Nancy J. Vickers, and the late Richard S. Ide.

The Bluebook: A Uniform SyStem OF Citation (Columbia Law Review Ass'n et al. eds., 17th ed. 2000) [hereinafter THE BLUEBOOK]. References to editions other than the most recent will be designated by edition number.

${ }^{2}$ See, e.g., Gil Grantmore, The Death of Contra, 52 STAN. L. REv. 889, 890 (2000) ("Student-edited law reviews rely heavily on tests of Bluebook skills in selecting new staff members ...."). At an April 2002 conference organized by LexisNexis for law journal editors, it was noted that almost all "top law schools" rely at least in part on bluebooking skills in choosing their editorial staffs. See E-mail from Dena Greenspan, Editor-in- 
For many, this selection process is their first exposure to an anxiety over citation and authority. The familiarity bred by that prolonged and intense exposure makes The Bluebook (and its attendant anxiety) a part of their history and mythology, a foundational text upon which legal culture is built."

Of course, this is no surprise. It is axiomatic that the air that eddies around law journal offices and the other spaces of legal academia is permeated with The Bluebook. Indeed, student editors of law journals spend an extraordinary amount of time yanking the articles and essays of legal academics into compliance with the dictates of The Bluebook. While it is true that some law schools and many courts do not follow The Bluebook's rules exclusively, ${ }^{4}$ The Bluebook is still firmly entrenched in its "authoritative position," particularly in the academic world. ${ }^{6}$ Because it is a structuring text that is inescapable even in its

Chief, University of Pennsylvania Law Review, to the Board of Officers of the University of Pennsylvania Law Review (Apr. 11, 2002) (on file with author) (outlining the selection criteria for participation on the law reviews of Boalt, Columbia, Duke, New York University, Northwestern, the University of Pennsylvania, the University of Virginia, and Yale).

${ }^{3}$ See Stephen R. Heifetz, Blue in the Face: The Bluebook, the Bar Exam, and the Paradox of Legal Culture, 51 RuTGERS L. REV. 695, 702-06 (1999) (noting that "[f]or over seventy years, law students have begun their journeys into the legal profession with The Bluebook in hand," and that it is an "important building block[] that [has] contributed to [an] important culture[]").

4 See Melissa H. Weresh, The ALWD Citation Manual: A Coup de Grace, 23 U. ARK. LITTLE ROCK L. REV. 775, 780 (2001) ("Many law review staffs have published either supplements or alternatives to the Bluebook [sic]. . . . [M]any jurisdictions have adopted specific citation rules for practice within that jurisdiction." (citations omitted)); see also A. Darby Dickerson, An Un-Uniform System of Citation: Surviving with the New Bluebook (Including Compendia of State and Federal Court Rules Concerning Citation Form), 26 STETSON L. REV. 53, $167-217$ (1996) (collecting citation rules from state and federal courts). The American Association of Law Libraries's 1995 report on citation formats stated:

The Bluebook: A Uniform System of Citation was expected to be used by counsel and/or judges in 33 jurisdictions.

Other sources of authority used were style manuals of particular states, which were expected to be used by counsel and/or judges in 15 jurisdictions; style sheets or memoranda, which were required in 5 jurisdictions; and court rules or statutes, which were expected to be followed in 15 jurisdictions. Only six jurisdictions had no expectation of use of any citation authority by either counsel or judges.

AALL Task Force on Citation Formats Report March 1, 1995, 87 LAW LIBR. J. 582, 590 (1995) [hereinafter Task Force] (citations omitted).

${ }^{5}$ Weresh, supra note 4 , at 781.

"See Task Force, supra note 4, at 590 ("The Bluebook [sic] is the overwhelming source of authority for legal citation form in academe. Virtually all academic law re- 
absence, a rather impressive literature has blossomed around it, comprising book reviews, ${ }^{7}$ diatribes, ${ }^{8}$ satires, ${ }^{9}$ and defenses of alternate systems of citation." As a text, The Bluebook has been called "[ $\mathrm{t}]$ he hypertrophy of law," ${ }^{11}$ likened to The Bible, ${ }^{12}$ Pilgrim's Progress, ${ }^{13}$ and a complicated statute. ${ }^{14}$ As a process, its development has been implicitly compared to the development of the common law. ${ }^{15}$

Most articles about The Bluebook treat it as an artifact, as an object to be evaluated. It is mocked, or critiqued, or dismissed. On occasion, however, scholars have looked behind The Bluebook, to examine accepted rules of legal citation that are codified in it. For example, in Semiotics, Analogical Legal Reasoning, and the Cf. Citation: Getting Our Signals Uncrossed, Ira P. Robbins investigates the use of a particular signal- "cf." - and the ways in which legal doctrine has turned on the interpretation of the implications of the signal itself. ${ }^{16}$ A few articles have investigated the legal citational footnote as a phenomenon,

views currently published require citation form to follow The Bluebook." (citation omitted)).

E.g., Warren D. Rees, The Bluebook in the New Millennium-Same Old Story?, 93 LAW LIBR. J. 335 (2001) (evaluating the Seventeenth Edition); Dickerson, supra note 4 (analyzing the Sixteenth Edition and suggesting improvements for the Seventeenth Edition); James W. Paulsen, An Uninformed System of Citation, 105 HARV. L. REV. 1780 (1992) (reviewing the Fifteenth Edition).

${ }^{8}$ E.g., Richard A. Posner, Goodbye to The Bluebook, 53 U. CHI. L. REV. 1343 (1986) (criticizing The Bluebook and serving as a preface to the first (and only) edition of The University of Chicago Manual of Legal Citation, known as the Maroonbook); see also infra note 27 (discussing the Maroonbook and how its rules differ from The Bluebook's rules).

${ }^{9}$ E.g., William R. Slomanson, Bluebook Review: A Uniform System of Citation, 28 ARIz. L. REV. 47 (1986) (reviewing A UNIFORM SYSTEM OF CitATION (Columbia Law Review Ass'n et al. eds., 14th ed. 1986)).

${ }^{10}$ E.g., Posner, supra note 8 (preferring the Maroonbook to The Bluebook); Weresh, supra note 4 (praising the ALWD Citation Manual, newly published by the Association of Legal Writing Directors).

${ }^{1 P}$ Posner, supra note 8 , at 1343 .

12 Jonathan M. Jacobson, A Uniform System of Citation, 43 BROOK. L. REV. 826, 826 (1977).

${ }^{19}$ Jim C. Chen, Something Old, Something New, Something Borrowed, Something Blue: The Bluebook: A Uniform System of Citation, 15th ed., 58 U. CHI. L. REV. 1527, 1527 (1991).

Id. at 1528.

${ }^{15}$ See Posner, supra note 8, at 1344 ("[A] large structure is built up, all unconsciously, by accretion ....").

${ }^{16}$ Ira P. Robbins, Semiotics, Analogical Legal Reasoning, and the Cf. Citation: Getting Our Signals Uncrossed, 48 DUKE L.J. 1043, 1045-47 (1999). Robbins demonstrates that the holding in Lambrix $v$. Singletary, 520 U.S. 518, 529 (1997), regarding the retroactive application of criminal procedure, relied in part on the notion that a "cf." citation implies weak support, or support by "dictum or by analogy" that does not control the result. Robbins, supra, at 1046. 
commenting on its overuse and overextension. ${ }^{17}$ These critiques and these analyses come from legal academia, most often from legal journals, and each of these approaches takes as its ground the idea that the rules of The Bluebook, though perhaps flawed and sometimes inefficient, are on the whole the sorts of rules by which citation should be governed. Thus, the conventional analysis tends to look at specific rules in The Bluebook and discusses their applications, their weaknesses, or their advisability. It is less common to probe and prod these rules for what they can reveal about the institution of legal citation itself. In such a project, The Bluebook becomes not so much an artifact as a code, in the semiotic sense-a system of signs that does not reflect "objective reality," but, rather, constructs a political and social grammar.

As a semiotic code, The Bluebook effectively hides ideological roots and assumptions behind a mask of necessity and naturalness. Consequently, a kind of skepticism is a foundational tenet of this Comment, which attempts, through textual analysis of The Bluebook, to reveal assumptions naturalized by the conventions of legal citation. It is not my project to suggest that these assumptions and their consequences should be exterminated or exchanged for others. ${ }^{18}$ Rather, they can

${ }^{17}$ See Arthur Austin, Footnote Skulduggery and Other Bad Habits, 44 U. Miami L. REV. 1009, 1011 (1990) [hereinafter Austin, Skulduggery] ("Authors have recognized that discerning, intelligent-or unethical-manipulation of footnotes can be a significant factor in achieving promotion, tenure, and status."); Arthur D. Austin, Footnotes as Product Differentiation, 40 VAND. L. REV. 1131, 1135 (1987) [hereinafter Austin, Product Differentiation] ("Footnoting has evolved from primitive origins and use as a 'pure' reference into an artistic and abstruse discipline that functions as a subtle, but critical, influence in the determination of promotion, tenure, and professional status." (citations omitted)); Abner J. Mikva, Goodbye to Footnotes, 56 U. Colo. L. REv. 647, 647 (1985) (calling footnotes in judicial opinions "an abomination"); Carol Sanger, Editing, 82 GEO. L.J. 513, 521 (1993) ("There is also the bizarre convention of law review footnoting, a growth industry we should not indulge."); Aside, Don't Cry Over Filled Milk: The Neglected Footnote Three to Carolene Products, 136 U. PA. L. REV. 1553, 1555 (1988) (describing "footnote three's contribution to the development of citation overkill in American law and the impending triumph of form over vulgar functionalism"); In Justice Breyer's Opinion, A Footnote Has No Place, N.Y. TIMES, July 28, 1995, at B18 (explaining why Justice Breyer does not employ footnotes in his opinions). But see Bryan A. Garner, Unclutter the Text by Footnoting Citations, TrIAL, Nov. 1997, at 87, 87 (suggesting that textual citations help mask logical incoherence in legal writing); William Glaberson, Legal Citations on Trial in Innovation v. Tradition, N.Y. TIMES, July 8, 2001, at A1 (noting that some who follow the movement, led by Bryan A. Garner, to move citation sentences in legal briefs and judicial opinions to footnotes "are making the switch to democratize the law because the public is put off by strings of numbers that can make legal prose seem even more impenetrable than it is").

${ }^{18}$ It should be noted that I write neither to praise The Bluebook nor to bury it; and though sometimes critical of the text, this Comment, far from eschewing The Bluebook's rules, cites according to its tenets. 
be examined for the insight that they give to legal culture and the construction of legal thought in the United States. Indeed, I suggest that the "anxieties" identified below might be a function of a legal system based in precedent and slow, deliberate accretion of legal rules. ${ }^{19}$

Specifically, I will examine the institution of the "string cite"-a citation sentence or clause comprising more than one signal and/or more than one authority within a signal-recognized in rule 1 of The Bluebook. ${ }^{20}$ Three subdivisions of this rule codify three of The Bluebook's fundamental precepts: rule 1.2, which sets up and defines introductory signals for legal citation; rule 1.3, which prescribes the order of signals within a single footnote; and rule 1.4, which establishes a hierarchy of authorities within each signal. Ostensibly formulated to communicate efficiently and clearly the "weight" of the authorities cited, and modeled on a hierarchical system in which the "strongest" go first, the rules governing the string cite serve to uncover a tension within legal scholarship: what I call (after Harold Bloom's "anxiety of influence") ${ }^{21}$ the "anxiety of authority."

In a Note in The Yale Law Journal, Kenji Yoshino effectively glossed Bloom's anxiety of influence:

The theory claims that all poets (writers) grapple with the anxiety that everything they write is influenced by their powerful predecessors. In

${ }^{19}$ The use of the word "anxiety," itself, to describe the phenomenon suggests its necessity to the system described. Slavoj Žižek (glossing Jacques Lacan) explains:

[A]nxiety occurs not when the object-cause of desire is lacking; it is not the lack of the object that gives rise to anxiety, but, on the contrary, the danger of our getting too close to the object and thus losing the lack itself. Anxiety is brought on by the disappearance of desire.

SLAVOJ ŽIŽEK, LOOKING AWRY: AN INTRODUCTION TO JACQUES LACAN THROUGH POPUlar Culture 8 (1991). Put in different terms, the object-cause of desire (which is, by definition, impossible for the subject to achieve) is represented as the goal of the drive. " $[\mathrm{T}]$ he real purpose of the drive is not its goal (full satisfaction) but its aim: the drive's ultimate aim is simply to reproduce itself as drive, to return to its circular path, to continue its path to and from the goal." Id. at 5 . To come "too close" to the goal is to realize the "lack of the lack" that produces anxiety. Thus, the object (inhering in The Bluebook) of a seamless and perfectly precise codification of standards of "authority" creates as a necessary by-product an anxiety about the very concepts of authority the codification seeks to ossify.

${ }^{20}$ See THE BLUEBOOK R. 1, at 21 ("Citation sentences and clauses may contain more than one signal. Signals are ordered according to rule 1.3. Individual citations following each signal are ordered according to rule 1.4.").

${ }^{21}$ For a general discussion of Bloom's "anxiety of influence," see HAROLD BLOOM, THE ANXIETY OF INFLUENCE: A THEORY OF POETRY (1973); HAROLd BloOM, KABALlaH AND CRITICISM (1975); HAROLD BLOOM, A MAP OF MisREAdING (1975); HaRold Bloom, POETRY and Repression: Revisionism from Blake to SteVEnS (1976). 
order to become great, Bloom asserts, poets must break free of this influence by conducting "strong misreadings" of their predecessors-that is, by subverting the meaning of their predecessors' texts in order to make their own contributions.

The anxiety of authority seems, at first blush, to be the polar opposite of the anxiety of influence, for it requires not that the predecessors' influence $(\mathrm{s})$ be shaken, but rather that the predecessors' work be shown to support and therefore authorize, on some level, the successor's text. However, Bloom's model necessitates that the successor situate herself in relation (even if only in counterrelation) to the predecessors' text(s), thus creating, or at least reinforcing, a tradition or genealogy. And this, too, is the project of the scholar who cites. The citing scholar embraces the comfort of authority, and authority therefore takes on added importance in her work. Spurred on by conventions of citation (such as those found in The Bluebook), authority becomes a source and a marker of anxiety. This anxiety ultimately reflects a confusion over what constitutes "authority" and "support" for a legal proposition, and inflames a debate within legal academia about the proper sphere and meaning of "expertise." Thus, this Comment identifies three specific anxieties attendant on the conventions of legal citation: the anxiety of authorities, the anxiety of relevance, and the anxiety of authoritativeness.

In tracing these anxieties, first this Comment will briefly rehearse the history of The Bluebook, focusing on certain challenges and changes as a way to identify some primary concerns of the debates over citation. The bulk of the remainder discusses rules 1.2, 1.3, and 1.4 of The Bluebook, as well as practices of legal citation not explicitly codified in the text, as a way to elucidate the aforementioned tensions within the legal academic community.

\section{THE BLUEBOOK AND AUTHORITY}

The development of The Bluebook from its inception in 1926 as a twenty-six-page pamphlet for use at Harvard Law School to its current status as a 389-page manual used at the vast majority of law schools in the country has been amply documented. ${ }^{23}$ Even so, there are some

${ }^{22}$ Kenji Yoshino, Note, What's Past is Prologue: Precedent in Literature and Law, 104 YALE L.J. 471, 473 (1994).

23 See, e.g., The BlueboOK: A SIXTY-FIVE YeAR RETrospective (1998) (containing text from all editions of The Bluebook); Dickerson, supra note 4, at 57-66 (discussing The Bluebook's history, spanning over seventy years); Paulsen, supra note 7 , at 1782-85 (describing the evolution of The Bluebook). 
occurrences in this history that deserve mention here. In 1949, the national conference of law review editors supported The Bluebook's adoption as a national system of citation, ${ }^{24}$ and in 1976 , The Bluebook's marketing strategy, theretofore focused on the academic world, expanded to include practitioners and the courts. ${ }^{25}$ The Fifteenth Edition, published in 1991, required for the first time that citations to books, articles, and student works include the author's full name; did away with most parallel citations to official state reporters; and revised the order of authorities within each signal (rule 1.4) so that constitutions and statutes preceded cases. ${ }^{26}$ The first major challenge to the supremacy of The Bluebook came from The University of Chicago in 1989, with the publication of The University of Chicago Manual of Legal Citation, known as the "Maroonbook." A further competitor has come onto the scene more recently with the publication of the ALWD Citation Manual. ${ }^{28}$ Interestingly, it has been suggested that a widely ma-

${ }^{24}$ Paulsen, supra note 7 , at 1783.

${ }^{25}$ Id. at 1784.

${ }^{26}$ Louis J. Sirico, Jr., Fiddling with Footnotes, 60 U. CIN. L. REV. 1273, 1276-77 (1992) (reviewing THE BLUEBOOK (15th ed.)). These changes survived into the Seventeenth Edition, as opposed to some changes of the Sixteenth Edition. See infra note 35 and text accompanying note 29 (outlining differences between the editions).

${ }^{27}$ The University of Chicago Manual of Legal Citation (The Univ. of Chi. Law Review \& The Univ. of Chi. Legal Forum eds., 1989) [hereinafter MAROONBOOK]; see also Posner, supra note 8 (containing a scathing commentary on The Bluebook and praising the Maroonbook). Posner's article in The University of Chicago Law Review included the Maroonbook as an appendix. Id. at 1353-68.

The Maroonbook vastly simplifies The Bluebook's rules. Its first and only edition, from 1989, has only sixty-three pages, inclusive of its index. Rule 3, which corresponds to The Bluebook's rule 1, occupies only a page and a half (to the Seventeenth Edition's nine-and-a-half pages). Rule 3.1 does not identify specific introductory signals, but allows an authority to be introduced without introduction, in the case of direct support, or by "an ordinary English phrase explaining its force and or purpose." MAROONBOOK, supra, R. 3.1, at 12. The rule for the order of authorities, which in The Bluebook is spread over rules 1.3 (order of signals) and 1.4 (order of authorities within each signal), allows authorities to "be organized in any manner that seems desirable." Id. R. 3.3, at 12 . It continues:

The most important authorities, or those most supportive of the argument being made in text, should usually appear first. Authority that supports the text only by analogy, or indirectly, should appear next, in a separate citation sentence introduced by language explaining how the authority supports the proposition made in text. Sources that provide only tangential support for the proposition in text should be omitted.

Id.

28 Ass'N Of Legal Writing Dirs. \& Darby Dickerson, ALWD Citation Manual: A Professional System of Citation (2000) [hereinafter ALWD MANUAL]. 
ligned change in The Bluebook inspired the creation of this latest manual.

In 1996, the Sixteenth Edition appeared, including within it momentous changes. A. Darby Dickerson, who was to become a prime mover behind, as well as an author of, the ALWD Citation Manual, explained these changes in measured language that eluded many commentators:

The editors substantially revised rule 1.2 on introductory signals. As they noted in the Preface, "The number of signals has been reduced and the distinction between signals has been simplified." Specifically, the "contra" signal and arguably the "e.g.," signal, have been deleted. The definitions for [no signal], "see," "accord," and "but see" have been altered. The primary fallout from these changes probably will be that the number of "[no signal]" cites will decrease and the number of "see" cites will increase, because "see" must now be used to show that the cited authority "directly states or clearly supports" the proposition. ${ }^{29}$

Because "[a]uthors use signals to indicate the purpose for which an authority is cited and the weight with which an authority supports or contradicts a particular proposition[,] [c] hanging what the signals mean effectively changes the substance of our common law." ${ }^{\text {"30 }}$ This change prompted an impressive outcry, as well as an impressive backlash, and the Association of American Law Schools passed a resolution formally opposing the changes and calling for authors, editors, and practitioners to disregard them. ${ }^{31}$ The resolution specifically pointed out the "weaknesses" of the process of editing The Bluebook. ${ }^{32}$. The widespread unrest over the Sixteenth Edition encouraged the ALWD to publish an alternative citation manual, "prepared by members of the legal writing community" ${ }^{33}$ in $2000 .^{34}$

${ }^{29}$ Dickerson, supra note 4, at 66 (quoting THE BLUEBOOK (16th ed.)) (footnotes omitted).

${ }^{30}$ Id. at 69 (footnotes omitted).

"Carol M. Bast \&c Susan Harrell, Has The Bluebook Met Its Match? The ALWD Citation Manual, 92 LAW LIBR. J. 337, 341-42 (2000); see Weresh, supra note 4, at 784 (noting that the "signals change [was] the impetus for the resolution").

Association of American Law Schools, Resolution Concerning Promulgation of Rules of Citation 1 (Jan. 4, 1997) (on file with author).

${ }^{33}$ Weresh, supra note 4 , at 786.

${ }^{84}$ The ALWD Citation Manual lists, in rules 45.2 and 45.3 , the signals and their uses. The contours of the lack of a signal are exactly coterminous with the Seventeenth Edition's definition. Compare ALWD MANUAL, supra note 28, R. 45.2(a), at 301 ("Do not use a signal if: (1) The cited authority directly supports the stated proposition [;] (2) The cited authority identifies the source of a quotation[; or] (3) The cited authority merely identifies the authority referred to in the text."), with THE BLUEBOOOK R. 1.2(a), at 22 (stating that no signal should be used when the "cited 
The seventeenth edition of The Bluebook reinstates the signals of the fifteenth edition with minor changes.

\section{LEGAL GITATION AND THE ANXIETY OF AUTHORITY}

Stepping back from the specific controversies of The Bluebook's citation rules, it is perhaps valuable at this point to review some major purposes of citation. Judge Posner has identified four purposes for having a system of citation:

The first is to spare the writer or editor from having to think about citation form .... The second purpose, which is self-evident, is to economize on space and the reader's time. The third, which is in tension with the second, is to provide information to the reader. The fourth is to minimize distraction. ${ }^{36}$

The American Association of Law Libraries Task Force on Citation Formats recognizes a longer list of principles of legal citation form, including uniqueness, brevity, eliminating redundancy, informativeness, reducing dissimilarity among forms, similarity to original, logic, permanence, readability/transcribability, tradition, standardization, simplicity of system, honesty, precision, public domain, longevity, and universality. ${ }^{37}$ Both Judge Posner and the Task Force note that The Bluebook's system of citation is not in compliance with many of these principles. $^{38}$ It is clear, however, that these are largely principles of

authority (i) directly states the proposition, (ii) identifies the source of a quotation, or (iii) identifies an authority referred to in the text"). Rule 45.3 lists the same signals as The Bluebook's rule 1.2(a)-(d), in the same order, except that "accord" and "see also" have been excised. The rule for ordering authorities within each signal evinces a complexity similar to The Bluebook's, however there is less attention to international and intergovernmental materials. Compare ALWD MANUAL, supra note 28, R. 46.4(a)-(c), at 30810 (containing as its only international or intergovernmental category, " $[t]$ reaties and international agreements"), with THE BLUEBOOK R. 1.4(a)-(i), at 25-27 (including a category of primary materials called "[r]esolutions, decisions, and regulations of intergovernmental organizations").

${ }^{35}$ The Seventeenth Edition's definition for "[no signal]" begins, "Cited authority (i) directly states the proposition," while the Fifteenth Edition uses the word "clearly" in place of "directly." Also, appended to the Seventeenth Edition's definitions for "see also," "cf.," "compare . . land] . . with . . land] . .," "but cf.," and "see generally" is a sentence urging the use of an explanatory parenthetical with each of these signals. See, e.g., THE BLUeboOK R. 1.2(b), at 23 ("Parenthetical explanations . . . following each authority are ... strongly recommended.").

${ }^{36}$ Posner, supra note 8, at 1344.

${ }^{37}$ Task Force, supra note 4, at 588-89.

${ }^{38}$ See Posner, supra note 8, at 1344-49 (arguing that The Bluebook's intricacy contravenes these purposes); Task Force, supra note 4 , at 589 ("[1]t is clear that the current 
the systematization of citation, and not principles of the institution of citation.

At its most basic, citation is a structure of indebtedness. Its purpose is simple attribution of ideas and expressions of ideas to authority outside of a specific text. This extraordinarily facile observation serves to re-emphasize that the quarrels over The Bluebook focus on the system and not the institution itself. This discussion begins at this basic level, with the suggestion that an analysis of the cover page of my "primary" text ${ }^{39}$-The Bluebook: A Uniform System of Citation (Seventeenth Edition) - can reveal a number of these assumptions about citation per se: (1) that citation to outside authority is necessary or at least advisable; (2) that there should be rules for this citation; (3) that these rules should be organized into a system, which implies a "logical" ordering; (4) that the system should strive for coherence and uniformity; (5) that the system should be laid out in one place, under one title; (6) that the system, though uniform, will change; and (7) that the system might have taken, and might still take, other forms. The comments by Judge Posner and the Task Force, and by most other commentators, concern assumption two and beyond, but leave the first - that citation is necessary or at least advisable - unaddressed.

It may seem difficult to question this most basic assumption effectively. The notion that citation to authority is necessary seems almost inescapable in a legal system based on precedent. If " $r$ ] easoning from precedent, the core of legal training [in the United States], shares with Burkean conservatism the assumption that what has been done before should be done again," exorably that the precedents reasoned from (and therefore outlining what should be done again) must be cited. It is possible, however, to imagine a tradition that does not find it necessary to make so brutally obvious the specific texts and authors that influenced or, in some cases, dictated the result of a case or inquiry. That such a system

system of legal citation, as reflected by the Bluebook [sic], conflicts with many, if not most, of these principles, and not just in the area of case citation.").

${ }^{39}$ Many (including myself) have quibbled with the necessity of making a distinction between "primary" and "secondary" texts or authorities, although The Bluebook implicitly endorses such a distinction in rule $1.4(\mathrm{i})$ by heading the category of sources "secondary materials." Paradoxically, The Bluebook, designated here as my "primary" text, is a "secondary material" under rule 1.4. Moreover, I might further argue that my real "primary" text is conventional legal citation, and The Bluebook, as a text that illustrates it, is somehow "secondary."

40 Heifetz, supra note 3, at 695-96. 
might be inefficient does not mean that it is impossible or even improbable.

Approaching the problem from this perspective, The Bluebook begins to signify more than its contents. We can take the very existence of The Bluebook (as a codification of the current system of legal citation) and its endorsement of a particular citation practice as a reflection that citation to authority is important. Indeed, citation to authority is so important that The Bluebook clearly contemplates that a single proposition will be supported by citation to more than one authority. Such a citation is commonly known as a "string cite," and is governed by The Bluebook's rules $1.2,1.3$, and 1.4. While judicial opinions fully exploit these three rules on occasion, the string cite receives its most complete expression in the work of legal academics, in the pages of legal journals. Much of the remaining discussion will focus on such texts.

\section{A. The Authority of Taxonomy}

Rules 1.2, 1.3, and 1.4 of The Bluebook are the scaffolding upon which the string cite hangs. As suggested above, rule 1.2, defining and implicitly ranking introductory signals, has been the subject of the most recent controversy. Rule 1.3 seems innocuous, simply making explicit that the order in which the signals appear in the preceding rule is the order in which they should appear in a citation sentence using multiple signals, and providing that the families of signals should appear in different citation sentences. Rule 1.4 identifies and ranks the authorities within each signal. Thus, these three rules function in tandem, sketching interlocking hierarchies.

Reviewers and commentators regularly bemoan the intricacies of The Bluebook, noting their peculiarity to the legal profession. ${ }^{41}$ These interlocking hierarchies are a significant source of its idiosyncratic complexity. Rule 1.2, for instance, which governs the "weight" that an authority throws behind the proposition it supports, includes in its taxonomy eleven discrete signals, ${ }^{42}$ and suggests that the yoking of sig-

${ }^{41}$ See Bast \& Harrell, supra note 31, at 339 ("The citation systems of other disciplines are far less complex."); see also infra text accompanying note 54 ("None of the citation guides used extensively in the Humanities, for example, includes a provision for distinguishing among the weights of authorities cited.").

${ }^{42}$ Note that these signals include the absence of a signal as first among the eleven enumerated: [no signal], e.g., accord, see, see also, cf., compare... [and] ... with... [and] . . ., contra, but see, but cf., and see generally. THE BLUEBOOK R. 1.2, at 22-24. 
nals may create even more. ${ }^{43}$ Though labeled "arcane and incomprehensible" ${ }^{44}$ by at least one commentator, this taxonomy strives to indicate with precision the particular manner in which cited authority lends its support. The assumptions inherent in this hierarchy are that an authority that does not directly support a statement should nonetheless be cited, and that it is necessary and proper to distinguish precisely among techniques by which an authority provides its support. And that is the apparent purpose of this classification system.

In his Preface to The Order of Things, Michel Foucault addresses the problem of classification, asking: "When we establish a considered classification, when we say that a cat and a dog resemble each other less than two greyhounds do ..., what is the ground on which we are able to establish the validity of this classification with complete certainty?" Implicit in this question is the presumption that classifications are established with certainty. And that makes perfect sense, for a classification would lack utility if the class it identified were not certain-that is, if class "A" were not clearly delineated from and (therefore?) defined against some other group that was "not-A." In order for a taxonomy to have meaning, its boundaries must be clear and certain. That almost goes without saying.

Confrontation with an "incredible" taxonomy, however, exposes the uncertainty of all classification. Foucault's collision is with a passage in Borges quoting from a Chinese encyclopedia dividing animals into fourteen categories: "(a) belonging to the Emperor, (b) embalmed, (c) tame, (d) sucking pigs, (e) sirens, (f) fabulous, (g) stray dogs, (h) included in the present classification, (i) frenzied, (j) innumerable, (k) drawn with a very fine camelhair brush, (l) et cetera, (m) having just broken the water pitcher, (n) that from a long way off look like flies." ${ }^{40}$ The collision with this improbable taxonomy demonstrates the limitation of our own system of thought ("the stark impossibility of thinking that"). ${ }^{47}$ These unnatural, uncertain classifications call into question our own naturalized distinctions. Moreover, " $[\mathrm{t}] \mathrm{he}$ central category of animals 'included in the present classification'...

49 See id. at 22 ('“E.g.' may also be used in combination with other signals, preceded by a comma: See, e.g., But see, e.g., ....").

${ }^{44}$ Thomas R. Haggard, Basic Citation Form, Part III, S.C. LAw., Sept.-Oct. 1998, at $13,13$.

4.) Michel Foucault, The ORder of Things: AN ARCHAEOlOGy OF THE HumaN SCIENCES, at xix (Vintage Books 1994) (1970).

${ }^{4 i}$ Id. at xv.

${ }^{47} I d$. 
is indication enough that we shall never succeed in defining a stable relation of contained to container between each of these categories and that which includes them all." ${ }^{48}$ This insight translates to the very concept of Order: "Order is, at one and the same time, that which is given in things as their inner law, the hidden network that determines the way they confront one another, and also that which has no existence except in the grid created by a glance, an examination, a language." Order, expressed in taxonomic categories, presupposes its own existence: We cannot begin to order the disordered without believing that Order is always already present, as much as we imagine that our taxonomies simply uncover logical, primordial rules of Order. We use taxonomy as a comfort, or, better, as a fetish, allowing us to believe in categorical certainty/discreteness/precision even in the knowledge of its absence. ${ }^{50}$ This paradox undergirds legal citation.

\section{B. Rule 1.2 and the Anxiety of Authorities}

The argument above helps to denaturalize/defamiliarize $e^{51}$ the taxonomy of signals, the primary placement of which (it is in the first rule in The Bluebook) would serve to ground it, to naturalize it as that

${ }^{48} I d$. at xvii.

49 Id. at $\mathrm{xx}$.

${ }^{50}$ See ŽIžEK, supra note 19, at 34-35 (discussing the "famous disavowal" je sais bien, mais quand même-I know very well, but all the same-that is constitutive of the fetish); Lee Edelman, Seeing Things: Representation, the Scene of Surveillance, and the Spectacle of Gay Male Sex, in INSIDE/OUT: LESBIAN ThEORIES, GAY THEORIES 93, 107 (Diana Fuss ed., 1991) ("[T]he problem engaged in the fetish is that of affirming a belief in presence over and against the knowledge of loss ...."). As Freud notes, fetishism can be determined "by the occurrence of an early deterrence from sexual activity owing to fear, which may divert the subject from a normal sexual aim and encourage him to seek a substitute for it." SIGMUND FREUD, THREE ESSAYS ON THE THEORY OF SEXUALITY 20 n.1 (James Strachey ed. \& trans., Basic Books 1962) (1925) (emphasis added). For example, "the foot represents a woman's penis, the absence of which is deeply felt." Id. at $21 \mathrm{n} .2$ (emphasis added). For a clearer discussion of the fetish, see 17 SIGMUND FREUD, From the History of an Infantile Neurosis, in THE STANDARD EDITION OF THE COMPLETE WORKS OF SIGMUND FREUd 7 (James Strachey ed. \& trans., Hogarth Press 1955) (1925).

"5l The concept of "defamiliarization" comes originally from Victor Shklovsky, for whom it was constitutive of poetic language--literary technique, that is, was a process of making strange the familiar. See Victor Shklovsky, Art as Technique, in MODERN CRITICISM AND THEORY: A READER 15, 27 (David Lodge ed., 1988) (calling "material obviously created to remove the automatism of perception" the "artistic trademark"). Such strange-making forces a "slowness of . . perception" that "gives satisfaction." Id. On a more general level, defamiliarization gives pleasure (and may produce anxiety) because it makes the reader see anew something she thought she understood, and suggests to her that it may actually mean something different than she assumed. 
upon which legal citation is based. And, if " $[c]$ hanging what the signals mean effectively changes the substance of our common law, ${ }^{, 52}$ if decisions and analyses are rendered based on the interpretation of these signals, ${ }^{53}$ then these signals are not only primary to legal citation, but also to our system of law itself. Citational signals, then, are not simply forms devoid of content, but constructions with import for, and impact on, the development of legal scholarship. But legal citation is alone in its insistence on this particular taxonomy, alone in the conviction that the writer must divulge the precise relevance of her authority. None of the citation guides used extensively in the $\mathrm{Hu}-$ manities, for example, includes a provision for distinguishing among the weights of authorities cited. ${ }^{54}$ And, the fact that each of the last eleven editions of The Bluebook has incorporated changes to the introductory signals ${ }^{55}$ emphasizes the taxonomy's vicissitude.

The taxonomy itself tells us that, in legal writing, not only sources that directly state a proposition must be cited, but also sources that say something related to the proposition. This "something" may be anything from "clear[] support[]," as in the popular "see" citation, to "analogous" support for the "cf." citation. ${ }^{56}$ Illustration and contradiction of various levels are also to be noted. There is an intense concentration on a notion of thoroughness (which includes the concept of "balance") and, more importantly, on attribution. In an ideal citation, fully utilizing the technology of rule 1.2 , contradictory authority, indirect authority, and, arguably, authority that has an even more distant relationship to a proposition in the text would be found and cited. And thus enters the string cite. ${ }^{57}$

${ }_{59}^{52}$ Dickerson, supra note 4, at 69.

${ }^{53}$ See generally Robbins, supra note 16, at 1045 (noting that the definitions of signals "affect the analogical reasoning process that is at the foundation of common law jurisprudence").

${ }^{24}$ There are three guides used extensively to govern citation practice in the Humanities: THE CHICAGo MANUAL OF STYLE (14th rev. ed. 1993); JOSEPH Gibaldi, MLA HANDBOOK FOR WRITERS OF RESEARCH PAPERS (5th ed. 1999); and JOSEPH GibALDI, MLA STyle Manual and Guide to Scholarly Publishing (2d ed. 1998). The last two are based on the same documentation style, but directed toward different audiences: the Handbook to high school students and undergraduates, the Style Manual to graduate students, scholars, and professional writers.

${ }^{55}$ See Bast \& Harrell, supra note 31, at 341 ("Each of the seventh through the sixteen [sic] editions contained changes in the introductory signals."). For a discussion of the changes reflected in the Seventeenth Edition, see supra note 35.

${ }_{56}$ THE Bluebook R. 1.2(a), at 22-23.

${ }^{57}$ A string cite that utilizes more than one signal is just one variety of this species. For a discussion of the citation containing a number of sources within one signal, see infra Part II.D. 
It is not at all unusual to find a citation using more than one signal. Indeed, and unsurprisingly, the comment on the use of the "see also" signal seems to require the use of multiple signals: "See also' is commonly used to cite an authority supporting a proposition when authorities that state or directly support the proposition already have been cited or discussed." Thus, a "see also" is most commonly used after and in addition to a "[no signal]" and/or a "see." This signal suggests that even an authority directly stating the proposition is not quite enough authority, and seems to stand for the proposition that, in the world of legal citation, more is better. "See also," then, putatively opposes "e.g.," (or "see, e.g.,"), the more economical signal used when "[c]ited authority states the proposition; other authorities also state the proposition, but citation to them would not be helpful or is not necessary." ${ }^{59}$ Even so, footnotes often use each of these signals in tandem. Professor Dickerson, "the recognized expert in legal citation," footnotes a clause remarking that the Fifteenth Edition's rule-change requiring the inclusion of an author's full name was "roundly criticized" with this string cite:

See, e.g., Paulsen, supra note 1, at 1792-93 (calling the rule "a little too rigid" and wondering: "[A] re we really supposed to provide a first name and middle initial any time we cite a source, even if the author does not provide that information?"); David E.B. Smith, Just When You Thought It Was Safe to Go Back into the Bluebook: Notes on the Fifteenth Edition, 67 CHI.KENT L. REv. 275, 277-78 (1991) (arguing that "[a]uthors should be able to get proper credit for their efforts without having editors mangle their names" (footnotes omitted)); see also infra note $154 .{ }^{62}$

Note 154 , to which we are directed by the "see also" signal, reads:

See Gordon, supra note 99, at 1700 (calling the change an improvement because " $[t]$ here are more than forty law professors named Smith, and

58 The Bluebook R. 1.2(a), at 23.

${ }^{59}$ Id. at 22.

${ }^{60}$ Weresh, supra note 4 , at 787.

i) Dickerson, supra note 4 , at 79 .

${ }^{62} \mathrm{Id}$. at $79 \mathrm{n.149}$ (alterations in original). This article appeared in 1996, after the publication of the Sixteenth Edition, and is the only article in the issue that conformed to its dictates. (Stetson Law Review had followed the suggestion of the January 4, 1997 Resolution Concerning Promulgation of Rules of Citation put forth by the AALS by disregarding the signals-changes of the Sixteenth Edition.) It is important to note that the changes to the rules for signals in the Sixteenth Edition have no bearing on this discussion. Though the "see" signal was modified to include authority that "directly states" a proposition, this change is irrelevant here. The "e.g.," signal in the Sixteenth Edition still indicated that citation to other authority was unnecessary, and the "see also" signal included no changes. 
of course nonacademics also write articles. I have a suspicion that the fourteen other law professors who share my surname have been really ticked off at me until now." (footnotes omitted)); Posner, supra note 56, at 1345 (urging that an author's full name be given-especially "in an era of multiple Ackermans, Dworkins, Epsteins, Whites, [and] Schwartzes"- "so that the reader will be in no doubt who the author isa bit of information that may tell him how much weight he wants to give the citation and whether he wants to look it up"); Paulsen, supra note 1 , at 1792 (agreeing that "first names help"). But see Sirico, supra note 3, at 1276. Sirico remarked:

I do not understand why the reader needs this information in a citation. He or she can find it by checking the cited material. In those occasional instances when the writer wants to insure that the reader knows the cited author is a prominent individual-for example, Harry W. Jones and not Buster Jones-the savvy writer can find a way to convey this information.

Id. (footnote omitted). ${ }^{63}$

The citation, beginning with a "see, e.g.," signal referencing two authorities, includes a "see also" referring to another note, which itself includes a "see" and a "but see." Leaving aside the question, not relevant to this discussion, of why support for the criticism of the rule change should include, after a "see also," praise for the change, and then, after a "but see," more criticism, the citations demonstrate the conjunction of signals, even when one that has been used is supposed to indicate that "citation to [other authorities] would not be helpful or is not necessary." rule directly. However, it does cite six passages from five different authorities. The fact that a "see, e.g.," introduces the footnote indicates that something odd, something else, is going on.

The footnote has encountered some harsh criticism in the past couple of decades, ${ }^{65}$ though the trend of excoriating it began much earlier. ${ }^{66}$ Perhaps the most common observation about the law review footnote is that it has proliferated and expanded beyond the bounds of necessity or decency. ${ }^{67}$ One author suggests that this phenomenon

${ }^{63} I d$. at $79 \mathrm{n} .154$ (alterations in original).

${ }^{64}$ THE BLueboOK R. 1.2(a), at 22.

${ }^{6.5}$ E.g., sources cited supra note 17.

${ }^{6 r j}$ See Fred Rodell, Goodbye to Law Reviews-Revisited, 48 VA. L. Rev. 279, 289 (1962) (referring to footnotes in law reviews as "phony excrescences").

${ }^{67}$ See Austin, Product Differentiation, supra note 17, at 1133 ("[Law review] articles are Typhoid Marys of an insidious plague-footnotes... What started as incidental and functional, footnoting is now thought to be a Frankenstein monster, rambling un- 
may stem from overzealous editing - a refusal on the part of editors to believe that "there are some things of which we can sensibly just take notice" without recourse to authority ${ }^{68}$-or from "the current trend toward compulsory parentheticals: the appalling reduction of an entire source into a phrase-a practice that burdens . . . an already bottom-heavy manuscript." ${ }^{, 69}$ Another plausible explanation arises in part from the invitation of rules $1.2,1.3$, and 1.4 to use multiple signals and multiple sources within footnotes. Certainly, the source-heavy citation gives the impression of completeness. Stringing authorities together to support a single proposition, sentence, or phrase in an argument suggests careful and thorough research, and insinuates that both the research and the citation are exhaustive. Moreover, the citation trailing off into a signal to indicate contradiction, such as "contra" or "but see," implies balance and even-handedness, for the author has even offered up authority that disagrees with her statement. This, in turn, can give the appearance of strengthening the support for the proposition, because the proffer of contrary authority hints that the author's confidence in her argument can withstand such weakening citation. Of course, another product of multiple-source citations is the added force lent by the specific sources cited.

Arthur Austin has stated, in a pair of articles, that footnoting in legal academia is largely self-serving, ${ }^{70}$ and that "opportunistic writers will exploit notes to cloak vacuous text." requires publication, and in which law reviews have proliferated, "authors rely on 'footnote differentiation' as the primary vehicle to distinguish their articles from those of their rivals." If citation is a technology that can set a writer apart from her colleagues, then there are a number of tools that aid in this process. Austin believes that the footnote, specifically the "Author's Note," is often used for networking purposes: acknowledging the help of famous and/or respected authorities gives the author credibility, the appearance of being "a contributing member in a 'network' of successful academics," and a

controlled at the bottom of the page ....”); Sanger, supra note 17, at 521 (characterizing footnoting as a "growth industry").

${ }^{68}$ Sanger, supra note 17 , at 521 .

${ }^{69}$ Id. (footnote omitted).

${ }^{70}$ See Austin, Skulduggery, supra note 17, at 1011 (stating that manipulation of footnotes can lead to promotion, tenure, and status); Austin,. Product Differentiation, supra note 17, at 1135 (arguing that footnoting is a scholar's most effective way to differentiate her work).

\footnotetext{
${ }^{71}$ Austin, Skulduggery, supra note 17, at 1030.

72 Austin, Product Differentiation, supra note 17, at 1136.
} 
greater likelihood of being reciprocally cited. ${ }^{73}$ Benefits, however, do not accrue only through acknowledgment in the personal Author's Note, but even through citation in a conventional footnote.

Legal citation, like most other citation systems, privileges the name of the author, which appears first in any citation of which it is a part. $^{74}$ But citation politics run in two directions simultaneously, benefiting both the cited and the citer. ${ }^{75}$ The cited gains the all-important citation, which is the "building block[] of academic stardom," and those in the academic trenches understand this. For example, in an article on "outsider scholarship," Jean Stefancic and Richard Delgado questioned a number of scholars (enumerated as "crits, radical feminists, [and] critical race theorists") ${ }^{77}$ about, among other issues, citation. Of eleven questions, three focused on citation and the remaining ones asked about publishing and job offers. ${ }^{78}$ Thus, the questionnaire placed the academic citation on a par with these other components and indices of academic success. Of course, what the cited gains is a free and effective advertisement.

The citer has something to gain, as well. Citing "newly discovered, unusual, or exotic" sources, ${ }^{79}$ for example, can increase an author's cachet. But citation to established authorities also adds something (even more?) to an author's reputation-beyond the actual support supplied by the authority, beyond the commonplace of giving the appearance of thoroughness, mentioned above. Attribution through citation

${ }^{73}$ Id. at 1145-46; see also Austin, Skulduggery, supra note 17, at 1022-23 ("Author's Notes may also facilitate 'conspiratorial cross-referencing' in which authors cite each other as experts to enhance everyone's reputation." (footnote omitted)).

${ }^{74}$ True, many legal texts are "unauthored" and thus cannot use the author's name as an organizing principle. However, the default position for legal citation is that the author's name, if available, precedes all other information about the cited rext. Unfortunately, this is not the Comment in which to deal with the phenomenon of legal "unauthorship," which occurs with texts like statutes and judicial opinions.

${ }^{75}$ For a fuller discussion of the citational politics discussed in the next few paragraphs, see Michael Bacchus, Eating Eve's Plums: On Citation and Hero-Worship, in QUeER Frontiers: MILlenNial Geographies, Genders, and Generations 278 (Joseph Boone et al. eds., 2000). The article deals with citation practice in the Humanities, specifically in Queer Studies, but the underlying theory applies to legal citation.

Id. at 282.

${ }^{77}$ Jean Stefancic \& Richard Delgado, Outsider Scholars: The Early Stories, 71 CHI.KENT L. REV. 1001, 1001 (1996).

${ }^{78}$ Id. at $1002-07$.

78. Austin, Product Differentiation, supra note 17, at 1147. 
corrals an author-complex for use in a paper, offering not only intertextual, but also extratextual aid, which is to say that, just as any specific citation adds its layer to the overall image of the [cited], the image of the [cited] ... becomes intertwined with the text in which it appears.

It matters what kind of authorities an author cites because those authorities are lending more than bare support to the proposition(s) for which they are cited. The "fugitive source" described above may aid in presenting an author's work as current, cutting edge, or "hip." On the other hand, utilizing the names of academic "stars" can "solidify and further expand establishment image," more valuable in a culture that is fundamentally conservative. ${ }^{82}$

Implicated in the citation to authority (i.e., "[a] source . . . cited in support of a legal argument"), ${ }^{83}$ then, is a concern about what constitutes effective support-that is, what constitutes authority (i.e., "an accepted source of expert information"). ${ }^{84}$ While this confusion must reign in any academic discipline, it is exacerbated in legal academia by the string cite and by the conventions of signaling that allow the presentation of many different levels of relevancy to function as support. An author might be able to work in citations to many different kinds of authorities in support of one proposition, covering the bases, as it were, of direct, clear, and analogic support, as well as of prestige, expertise, hipness, and amateurishness. Far from resolving the question, however, such pilings further problematize these relationships, paradoxically emphasizing the differences in weight and in authorial signature by linking them together in one long citation sentence. Look, for an example, to footnote eighty-two in this Comment, which manages to mention six authors' names-two of them among the

${ }^{80}$ Bacchus, supra note 75, at 286-87.

${ }^{81}$ Austin, Product Differentiation, supra note 17, at 1146-47.

${ }^{82}$ See Heifetz, supra note 3, at 695 ("[T] he essence of the legal culture in the United States is a backward-looking, Burkean conservatism."); $c f$. Bacchus, supra note 75 , at 292 (noting that that which is authority is necessarily no longer oppositional or cutting-edge, and thus that "authority" is always already a conservative construction); Stefancic \& Delgado, supra note 77, at 1011 (documenting the difficulties of nonEstablishment scholars in academic publishing and promotion, and publishing a letter from Catherine MacKinnon to the authors stating that "[ $n$ ]one of it is past, lost in the bad old days"). The assertion that law faculties and academic legal departments are fundamentally conservative may be a tautology. Law schools, after all, are primary sites of teaching "the law," that most established of institutions. Additionally, and perhaps consequently, such a statement may be one of those "things of which we can sensibly just take notice." Sanger, supra note 17, at 521.

${ }^{89}$ BLACK'S LAW DICTIONARY 129 (7th ed. 1999).

${ }^{84}$ AMERICAN HERITAGE DICTIONARY 121 (4th ed. 2000). 
most famous professionals in legal academia, and one (unquestionably amateur) who has not been heard from until now. Richard Delgado's and Catherine Mackinnon's names, because of their fame, would seem necessarily to add more ballast to an assertion, even if introduced by a weaker signal, or simply included in a parenthetical. The fact that they are preceded by my own name in the same "cf." clause, and by the name of a practitioner from the U.S. Department of Justice in an earlier (and stronger) clause creates an illusory hierarchy of authority, in which Heifetz should provide the weightiest, and then Bacchus, followed by Stefancic and Delgado, with MacKinnon adding just a soupçon at the end. Such confusion, enabled by the conventions of signaling, adds to and indexes the anxiety of authority (read: the anxiety over the relationship between expertise and relevance in authority) in the texts of legal academia.

\section{Rule 1.3 and the Anxiety of the Relevance of Authority}

We might, then, gloss this formulation of the anxiety of authority as an anxiety over the prestige of the authority. Clearly, however, it is affected by the interlocking hierarchies of the string cite, particularly by the ordering of the weight of relevance, codified in rule 1.3 , and the discussion above implicitly recognizes the role played by the ordering of signals in this construction. But rule 1.3 also presents another face of the anxiety of authority, betraying a clear anxiety about relevance.

According to the rule, signals must be ordered with the weightiest first. Thus, direct statement ("[no signal]," "e.g.,") precedes clear support ("accord," "see"), which comes before additional support ("see also") and analogous support ("cf."). There is an obvious presumption in favor of direct statement or clear support, and this makes perfect sense. Indeed, it seems that the definition of the fifth strongest supporting signal, "see also," implies that a stronger signal has gone before it. This requires, then, that all citations indicating support must begin with, at least, the fourth strongest signal, "see," which indicates clear support. $^{85}$ Thus, The Bluebook actually mandates clear or direct support. This imperative leads "authors to characterize their strongest authority as clear support," even if this is an overstatement of their confidence in the authority.

\footnotetext{
${ }^{85}$ See Robbins, supra note 16, at 1073 (concluding that “[e]very writer's first source must . . . constitute clear support").

${ }^{86}$ Id. at 1074 .
} 
This anxiety about relevance affects other signals, as well. Interpreted as above, rule 1.3 urges that citations begin with the "strong" signals (i.e., "[no signal]," "e.g.," "accord," "see"). One might argue that a proposition supported by a single signal of less weight (i.e., "cf.") does not have enough support to be convincing. ${ }^{87}$ And that suggests that bare citational support is not appropriate, but instead that fuller discussion and explanation is required. ${ }^{88}$ What this argument recognizes is that the rules of order create a situation in which certain signals that putatively indicate support can actually serve to deny support to a proposition. A weak signal, such as "cf." calls attention to its weakness because of the presumption in favor of stronger support. An author's attitude toward an authority preceded by such a signal is interpreted as ambivalent, or, at best, ambiguous. This particular supporting signal seems to slide down page twenty-three of The Blue$b o o k$, descending from a signal that indicates support to one that indicates contradiction. ${ }^{89}$

The "cf." citation, then, like the "see also" citation, might have its primary utility as part of a larger citation sentence. And so, the two signals would regularly be used only after signals indicating stronger support. In such a situation, however, the anxiety of relevance still obtains. Placed following stronger signals, these weaker ones still indicate a lack of confidence in the authority's support, which inspires a questioning of the relevance of the cited authority. As a citation sentence tapers off, its utility becomes less and less apparent, and the thin end seems a makeweight, generally unnecessary except, perhaps, for ballast.

But what about balance? That is the apparent province of an even more distant part of the citation, the signals indicating contradiction, which are relegated to a separate citation sentence after signals indicating support and the "[s]ignal that suggests a useful comparison."

${ }^{87}$ For a discussion of judicial opinions that make use of exactly that argument, see id. at $1045,1056-72$.

${ }^{88}$ The Bluebook does suggest that authority preceded by the "cf." signal include a parenthetical explanation of its relevance. THE BLUEBOOK R. 1.2(a), at 23. Robbins suggests that The Bluebook, instead, requires "relevant and substantive" parentheticals after a "cf." signal, explicitly "promot[ing] this goal of reasoned elaboration." Robbins, supra note 16, at 1076-77. The parenthetical would then become an argument in support of the proposition, which is supposedly supported by the authority.

${ }^{89}$ Robbins even points to a case in which a "cf." signal is interpreted as negative authority. See Robbins, supra note 16, at 1069 n.129 (citing Judge Easterbrook's concurring opinion in Czerkies v. United States Department of Labor, 73 F.3d 1435, 1447 (7th Cir. 1996)).

${ }^{90}$ THE BlueboOK R. 1.2(b), at 23. 
The efficacy of including authority that contradicts a proposition in the text, however, remains unclear.

Black's Law Dictionary construes "authority" as something that supports an assertion. ${ }^{91}$ The Bluebook, at first, seems to suggest likewise, stating in rule 1.1 that "[i]f a footnote itself contains an assertion requiring support, a citation for the relevant authority should appear directly after the assertion." ${ }^{92}$ The absence of any mention of contradiction implies that "citation for the relevant authority" is useful only for support. Later in the rule, however, the parenthetical "(or contradict)" is included after the word "support": "Authorities that support (or contradict) an entire sentence are given in a separate citation sentence immediately after the sentence they support (or contradict),"93 for example. "Authority," then, expands to include that which does not support. Importantly, however, it does not include only that which directly contradicts, for among the three signals indicating contradiction is the slippery "but cf.," which is to be used when "[c]ited authority supports a proposition analogous to the contrary of the main proposition." A4 Authority introduced by a "but cf." has extraordinarily attenuated relevance to the proposition asserted in the text.

Note, too, that the rule has slipped back into the language of "support." Each of the signals in rule 1.2(c) elides contradiction by speaking of support. For "contra" the authority "directly states the contrary of the proposition"; for "but see" it "clearly supports a proposition contrary to the main proposition." tion" "support[ed]" by the "[c]ited authority" is not a proposition included in the argument being made by the text. Rather, it is a phantom proposition, the existence of which is suggested by the fact of its opposite. The impetus to include authority indicating contradiction may be to give the appearance of balance, to highlight the fact of disagreement on an issue, or to indicate disapproval of a theoretical or doctrinal stance, or of its proponent. ${ }^{96}$ Whatever the motivation,

${ }^{91}$ See supra text accompanying note 83 (defining "authority" as "[a] source... cited in support of a legal argument" (alteration in original)).

92 THE BLUEBOOK R. 1.1, at 21.

33 Id. R. $1.1(\mathrm{a})(\mathrm{i})$, at 21.

${ }^{94} I d$. R. $1.2(\mathrm{c})$, at 23.

95.

${ }^{96}$ None of these motives is clearly convincing. Citing contradictory authority to provide balance can be a way simply to avoid significantly addressing opposing arguments. After all, if the opposing arguments were addressed in the text, authorities cited would use rule 1.2(a) signals indicating support. Balance, therefore, becomes 
however, the signals themselves masquerade as supporting, for they are supporting something, even if it is something akin to the opposite of the assertion the author is trying to prove. Thus, material that is clearly substantively irrelevant to convincing a reader of the point an author is trying to prove is cloaked in the language of relevance and support. Perhaps here, near the terminus of the citation paragraph, the place of dishonor, is the clearest evidence of the depth of the anxiety of relevance in law review citation.

\section{Rule 1.4 and the Anxiety of Authoritativeness}

The most intricate and detailed of the interlocking hierarchies of rule 1 is rule 1.4, governing the order of authorities within a signal and covering three pages in The Bluebook. Commentators had complained about this seemingly rigid hierarchy, ${ }^{97}$ and rule 1.4 is now prefaced with a disclaimer of sorts: "If one authority is considerably more helpful or authoritative than the other authorities cited within a signal, it should precede the others. Absent this or some other substance-related rationale for placing one authority before another, cite authorities in the order in which they are listed below." Clearly, the rule is written according to the precept that more authoritative sources should come before less authoritative ones, and so the "order . . listed below" tracks a generally-held conception of the relative authoritativeness of different generic sources. ${ }^{99}$

illusory. Alerting the reader to disagreement on an issue seems unnecessary, as a proposition upon which there were no disagreement would be axiomatic, and would require no authority at all. Including contradictory authority as a gesture of disapproval becomes a citation to authority that the author wants the reader to discount or ignore. See, e.g., Grantmore, supra note 2, at 889 ("Once upon a time, truth was truth, and we had a way to signal what wasn't."). Including such authority asks the reader to pay no attention to that man behind the curtain. It is possible that the motivation is more akin to that discussed in Part II.B, supra: to give the appearance of thoroughness, and to place an author as part of an intellectual circle.

97 See, e.g., Posner, supra note 8, at 1347 ("There is no need to have rules about the order in which authorities are cited in a string citation. There is a natural order that depends on the purpose of the string citation and the contents of the cited works."). I say that the hierarchy is "seemingly" rigid because it has, actually, evolved. The Fifteenth Edition, for example, revised this order, mandating for the first time that constitutions and statutes precede cases. Sirico, supra note 26, at 1277.

${ }^{98}$ THE BLUEBOOK R. 1.4, at 25.

${ }^{99}$ Note that the "considerably more helpful" and "substance-related" criteria are, of course, context-driven, and could not be a basis for a generalized rule of order. Note, too, that the prescribed ordering is not, however, devoid of meaning or controversy. Sirico observes, for instance, that the decision to rearrange the hierarchy so that constitutions and statutes precede cases "may reflect a judgment that we have moved 
As with the other rules discussed in this Comment, rule 1.4 clearly contemplates that more than one source will be used to support a single proposition. This rule even assumes that more than one source will support a single proposition with the same weight of relevance, for it mandates order within a signal. And, certainly, that is sometimes true. Take, for instance, a citation from a Comment recently published in the University of Pennsylvania Law Review. Asserting that thirty-four states currently have "antidilution" laws, the footnote lists, after a "see," all of the statutes in alphabetical order by state. ${ }^{100}$ Such a citation is clearly useful, informative, and even necessary according to the prevailing conventions of legal citation.

In contrast to the "necessary" string cite is the "discretionary" string cite-a citation that lists a number of sources to support one proposition. The practice of stringing multiple signals together in this sort of footnote has been discussed above in Part II.B, but such a technique is also used with only one signal. The motivations may largely be coterminous with those mentioned earlier. However, there are some slight differences when the sources are being cited within one signal, which means that each has the same weight of relevance. After a "[no signal]"101 or a "see," a list of authorities must either "directly state[]" or "clearly support[]" the proposition. Referring to many sources in either of these cases would strengthen support by showing that the proposition is widely held (or, even, widely held by a number of influential people). But, as the number of sources cited approaches infinity, the need for even a single source fades, because a belief so solidly entrenched hardly requires authority to support it. These citations, then, must tread carefully, balancing the interest of collecting support that convinces with the danger of making that support seem unnecessary or indulgent. Moreover, one or perhaps two

from the era of the common law to the era of statutes." Sirico, supra note 26, at 1277. Paulsen complains that the hierarchy, which relegates state courts to "second-class citizenship," is a symptom of The Bluebook's "bad case of federal parochialism." Paulsen, supra note 7, at 1788 .

${ }^{100}$ Paul Edward Kim, Comment, Preventing Dilution of the Federal Trademark Dilution Act: Why the FIDA Requires Actual Economic Harm, 150 U. PA. L. REV. 719, 726 n.35 (2001).

${ }^{101}$ This rarely happens, at least at the University of Pennsylvania Law Review, where "[no signal]" seems to be narrowly construed and used almost exclusively to identify the source of a quotation or identify an authority mentioned in the text, neither of which would allow a list of sources. The case of an authority "directly stat[ing] the proposition" is illustrated primarily by a source providing statistics, which are then used in the text. Thus, this is the only case in which a "[no signal]" might contain more than one authority. 
"authoritative" sources that directly state or clearly support a proposition would seem to obviate the need for more. Indeed, this kind of citation overkill is almost certainly symptomatic of the anxiety of authority, betraying an uncertainty about authority (e.g., how much to cite, and to whom to cite) that paradoxically subtracts from the proposition's support.

But the observation that a single "authoritative" source should really suffice is meaningless if the concept of authoritativeness is unstable. Authoritativeness is supposed to be reflected in rule 1.4's hierarchy. But, all hierarchies are ideological, and rule 1.4 is no different. It may seem so obvious as to be unquestionable that a constitution is more authoritative than a statute, which is more authoritative than case law, because the constitution can trump the statute, which can trump the case law, while the reverse is not generally true. But this ignores the fact that the U.S. Constitution is interpreted in case law (as are statutes), and it is more often U.S. Supreme Court decisions that define rights and obligations than the rather vague and poetic foundational document. The decision to assert the primacy of a constitution over a case in the hierarchy, then, might reflect the notion that we have moved from a common law era into a statutory one, ${ }^{102}$ or it might be a product of the need for the illusion of certainty in American law and the comfort of the idea that law springs from a single document and not from a tangle of opinions coming out of a warren of courts.

This Comment, however, is more concerned with the work of legal academics, both in citing and in being cited to, than the professional opinions of judges. Accordingly, I turn now to the section of rule 1.4 that establishes the hierarchy of the work of legal academics: rule 1.4(i), describing the order of "secondary materials." The rule moves through nine categories, from model codes and restatements all the way down to electronic sources (presumably those that are not available in print). ${ }^{103}$ Of particular interest are categories two through five:

${ }^{102}$ See supra note 99 (discussing Sirico's opinion that "we have moved from the era of the common law to the era of statutes"').

${ }^{103}$ See THE BLUEBOOK R. 18, at 129 (“[T] raditional printed sources" should be used and cited, "except when the information is not available in a printed source, or if the traditional source is obscure or hard to find .... In the latter case ... the traditional source should be used and cited, and the electronic source may be given as a parallel citation ...."). 
(2) books, pamphlets, and shorter works in a collection of a single author's works (alphabetically by last name of author; if none, by first word of title)

(3) works in journals (not magazines or newspapers), including forthcoming works and shorter works in a collection of various authors' works (alphabetically by last name of author)

(4) book reviews not written by students (alphabetically by last name of reviewer)

(5) student-written law review materials including book reviews (alphabetically by last name of author; if none, by first word of title; if none, by periodical as abbreviated in citation). ${ }^{104}$

Pride of place is given to the author of a book, pamphlet, or collection, and single-authorship of an entire publication seems to be the distinguishing characteristic. As well as preceding other "authored" secondary materials, ${ }^{105}$ these sources are differentiated in footnotes by typeface conventions, for both the author's name and the title of the publication appear in large and small capital letters. ${ }^{106}$ The remaining sources listed in this rule do not get the distinction of that typeface, but are cited with the author's name in ordinary roman type and the work's title in italics. ${ }^{107}$ Thus, the rule privileges as authoritative the singly-authored, self-contained work, suggesting, somewhat problematically, that a work that stands alone has a greater claim to expertise than a work that is included in a collection by various authors. ${ }^{108}$

Expertise is again at issue in the next category, that of the academic journal, which excludes from its parameters work that appears in magazines or newspapers, presumably generally written by journal-

${ }^{104}$ Id. R. $1.4(\mathrm{i})$, at 27.

${ }^{105}$ Model codes and restatements, which precede even singly-authored publications, are "unauthored" works, that is, works without an authorial signature.

${ }^{106}$ THE BLUEBOOK R. 2.1 (b), at 31; see also id. R. 15.5.1 (b), at 112 (mandating the use of large and small capitals for the author's name and the title of the volume for shorter works in a collection by a single author, while requiring the use of italics for the title of the shorter piece).

${ }^{107}$ See, e.g., id. R. 16.6, at 121-23 (describing the proper typeface for non-studentwritten book reviews, student-written law review materials, and student-written book reviews).

108 While it could be hypothesized that the rule implies that singly-authored longer works have the authoritative upper hand, the inclusion of the pamphlet makes it clear that self-containment is the operative consideration. But cf. FOUCAULT, supra note 45, at xix-xx ("On what 'table', according to what grid of identities, similitudes, analogies, have we become accustomed to sort out so many different and similar things? . . . [T] here is no similitude and no distinction ... that is not the result of a precise operation and of the application of a preliminary criterion."). 
ists and lay people and not by experts in the substantive field of the article. The academic journal is set apart from other periodicals (an interesting separation in this discipline, given the way that law reviews are edited), ${ }^{109}$ and, importantly, professional academic authorship is set apart from amateur authorship. Relegated to category five are all "student-written law review materials," which are superseded even by book reviews, as long as they are not written by students. There is some inconsistency here, as law reviews are journals, and category three purports to govern works in journals and does not make an exception for student-written work. It is unclear, too, where a book review written by a student (as many are) in a journal that is not a law review would appear: as a book review, it should be a part of category four, except that it is student-authored; as student-written material, it might be category five, except that it is not law review material; so perhaps it belongs in category three, as a work appearing in a journal that is neither a book review not written by a student nor studentwritten law review material.

But the point here is not to bemoan the ambiguity of one of The Bluebook's rules-that has been left to greater minds than mine. ${ }^{110}$ Instead, I see the attempt at exactness in this rule as an index of the anxiety of authoritativeness in legal citation. After all, where the rule runs into trouble is in its effort to cordon off student-written material from non-student-written material, that is, from material written by professionals (or, better, by professors?). What is the difference between students who write in academic journals, including law reviews, and professionals who do?

Focusing on legal journals, and assuming, for the sake of argument, that most of those who are published in legal journals are law professors or law students, a number of possibilities come to mind. At the University of Pennsylvania Law School, the law faculty is overwhelmingly white and male. The student body is substantially more diverse. So, perhaps the difference between the two groups is gender, race, and ethnicity. Thus, the privileging of the professionally-written material over the student-written material trickles down to become a privileging of white male authority. This is an interesting hypothesis, but, while it might obtain at Penn Law, it may not be the case at other

${ }^{109}$ See infra Part III ("[A]cademic legal journals are not peer-refereed, but, rather, are edited by students.").

${ }^{110}$ See, e.g., supra notes 7-15 (citing literature by Rees, Dickerson, Paulsen, Posner, Slomanson, Weresh, Jacobson, and Chen). Of course, I am using a notion of "greatness" that seems to be endorsed by rule 1.4 (i). 
law schools." More likely, the distinction reflects a decision that the professional has a greater claim to authority than does the amateur.

But, again, the rule itself serves to undermine this decision. In separating the two kinds of authors, the rule seeks to ensure that their authority will not be confused. The student author should always appear after (i.e., in a position inferior to that of) the professional academic author. ${ }^{112}$ But, in its enthusiasm to ghettoize the student author, the rule recognizes the clear possibility that she truly might be confused with her professor, that her work actually might evince the attributes necessary to represent and constitute authoritativeness. If the student's work is "considerably more helpful or authoritative" than her professor's, then the rule allows it to be cited first. However, in the absence of such a context-based reason, if all else is equal, the default position is that the student's work follows her professor's. That is, professional status stands as a proxy for authoritativeness, and the professional author takes precedence over the student (writing as a student). And, here I use the term "professional" in two ways, simultaneously, designating both an author who is engaged in a "profession," such as the legal profession, and a person who works primarily as an author. Rule 1.4(i) tells us that both kinds of authors, whether academic or "creative," are likely to occupy the place of authoritativeness in a one-signal string citation. Rule 15.5.1(b) emphasizes this by illustrating the citation form for shorter works in a collection by a single author (category two of rule 1.4(i)) with a sample citation to Adrienne Rich's Transcendental Etude, included in her volume of poetry, The Fact of a Doorframe. ${ }^{113}$ Thus, the primary focus is on the author, as opposed to her work, and the primary way for sifting through authors is by focusing on their professional status. Conventions of legal citation seem to allow the use of this technique to avoid actual evaluation of authoritativeness, perhaps because it is not clear how legal acade-

"II See Lani Guinier et al., Becoming Gentlemen: Women's Experiences at One Iry League Law School, 143 U. PA. L. REV. 1, 2 n.2 (1994) ("Our research is only about the University of Pennsylvania Law School and may not apply to other institutions of legal education which do not share Penn's history, dominant first year pedagogy, and predominantly male faculty.").

${ }^{1} 2$ There are imaginable cases in which the hierarchy would require citation of student-written material before, say, the work of a tenured law professor: for example, when an established authority writes a newspaper or magazine article. In this case, the academic author has become an article writer and will be cited below even studentwritten law journal material. Rule 1.4 's "escape clause" could "correct" that order.

${ }^{118}$ THE BLUEBOOK R. 15.5.1(b) , at 112. 
mia should determine authoritativeness and negotiate the divide between expert and amateur.

\section{III. “AMATEURITY” AND AUTHORITY}

In legal academia, the relationship between the amateur and the professional is unusually troubled. Though this may be due in part to idiosyncrasies of American law school classroom pedagogy (as opposed to that of other types of American graduate schools), it likely has more to do with the power that amateurs (i.e., law students) have vis-à-vis professionals (i.e., law professors) outside of the classroom. This power derives from the governance of the primary organs of legal scholarship in America-academic legal journals.

In contrast to the academic journals of other disciplines, academic legal journals are not peer-refereed, but, rather, are edited by students. Law students serving as editorial board members have the responsibility not only of editing articles accepted for publication, but also of actually doing the selecting. In other respects, however, legal academic publishing resembles the academic publishing of other disciplines. That is to say that the pressure on faculty to publish is just as great in legal academia as it is elsewhere in academia. ${ }^{114}$ Decisions made by law students, then, have a considerable effect on the careers of law professors. In some ways, amateurs function as the gatekeepers to professional advancement-a delicious irony given the strictures of rule $1.4(\mathrm{i})$.

As a result, academic professionals have taken to commenting on the role of students in academic legal publishing, stressing the amateur status of law review editors, that is, stressing the putative difference, discussed above, between amateur and professional. ${ }^{115}$ Even so,

114 See Austin, Skulduggery, supra note 17, at 1015 ("Competition exploded on the supply side when pre-tenure faculty were forced to "publish or perish.'”); Sanger, supra note 17 , at 516 ("The work of junior colleagues is regularly reviewed as part of standard time grade requirements. Most of us agree that scholarship sensibly contributes to decisions about tenure, promotion, and hiring."); Elyce H. Zenoff \& Lizabeth A. Moody, Law Faculty Attrition: Are We Doing Something Wrong?, 36 J. LEGAL EdUC. 209, 220 (1986) (noting that publication of legal scholarship is a primary criterion for tenure).

${ }^{115}$ Professor Sanger writes:

Let us start with the editors themselves. They are often young, a good recommendation for many activities, though not necessarily editing. They are also students, which means in most cases that they are not as familiar (or not at all familiar) with the substantive issues of a particular paper.... Few are trained as editors or plan to make a career out of it. Most student editors have 
the predominance of student-edited law journals in the United States means that amateurs regularly make decisions about the professional work of professionals. Professionals, in turn, look to the decisions of these amateurs in determining the professional development of their colleagues. ${ }^{116}$ In this milieu, the amateur has an extraordinary and unusual claim to authority and, indeed, authoritativeness.

Many who begrudge the implications and consequences of the student-run law review, however, concede that there is a text on which the law student is an expert: The Bluebook. Citation format can be a source of argument between authors and editors, but these are arguments in which the editor is likely to prevail, given her "superior grasp of Bluebook arcana." 117 This expertise is bred of familiarity. Law journal editors are saddled with poring over a manual of citation-The Bluebook-as part of their regular duties. Interestingly, however, some of these same editors are also responsible for editing this manual of citation and have been subject to charges of ineptitude or amateurity. ${ }^{118}$ A repeated complaint about The Bluebook seems to be that the

likely had no editorial experience before sitting down to your paper other than having had their own work hacked to bits by students who experienced the same thing the year before.

Sanger, supra note 17, at 517; see also Austin, Skulduggery, supra note 17, at 1014 (mentioning that "[1]aw journal editors... [are] disdained as students and chastised for their 'neophytic judgment," and noting that they "lack[] the experience of professionals" (footnote omitted)).

Another commentator, identified in the Author's Note as an executive editor of the Harvard Law Review from 1990 to 1991, asserts (albeit facetiously) that the relationship between law review editors and authors is even more tense, stating, "Editors and professors distrust each other with an intensity that dwarves the animosity displayed in some marriages, most divorces, and all prenuptial contracts." Chen, supra note 13, at 1534.

${ }^{116}$ It has even been suggested that students "write" articles attributed to professionals. Sanger cites a false story "reporting ... that the tenure piece of a junior professor had been ghostwritten by student editors," Sanger, supra note 17, at $514 \mathrm{n} .6$, and later complains that "articles are too frequently transformed from something written by an author with a distinct voice, point of view, and line of argument to something closer to a composition by student committee," $i d$. at $\mathbf{5 1 7}$.

${ }^{117}$ Chen, supra note 13, at 1535; cf. Grantmore, supra note 2, at 890 ("Studentedited law reviews rely heavily on tests of Bluebook skills in selecting new staff members .....").

${ }^{118}$ See Pamela Lysaght \& Grace Tonner, Plain Language: Bye-Bye Bluebook?, 79 MICH. B.J. 1058, 1058 (2000) (“[I]nstead of striving for consistency and stability when adding citation formats for new sources, successive editorial boards [of The Bluebook] seemingly sought to put their imprint on new editions and made pointless, frivolous changes ...."); Weresh, supra note 4, at 784 ("[T] he release of the Sixteenth Edition has revealed weaknesses in a process that leaves this significant subject within the unilateral control of law students...." (citation omitted)); of. Posner, supra note 8, at 
law reviews that are in charge of its editing cannot follow its format. ${ }^{119}$ Stewardship and editorship of The Bluebook, then, do not confer authority, though study might. The ALWD Citation Manual makes abundantly clear that the struggle over citation form is a struggle between amateurs and professionals. The President of the ALWD who presided over the beginning stages of the new manual hankered for a guide "prepared by professional legal writing teachers and librarians, in a joint effort-not a student-written and poorly organized Bluebook." ${ }^{\text {120 }}$ The editors consequently chose to subtitle the manual "A Professional System of Citation."

\section{ANXIETY AND (IN)STABILITY}

In legal academia and publishing, the bases of and relationships between the amateur and the expert, the "neophyte" and the professional, are notably unstable. And it makes some sense that the concept of authority would become a focus in a discipline in which these constructions are fissured, if not fractured. Current citation form, as embodied in The Bluebook, and current citation practice, as demonstrated in law journals across the country, seem a symptom of this concern, here pathologized as anxiety. The Bluebook begins the discussion about citation form, in its rule 1 , with the extraordinarily intricate and interestingly idiosyncratic mechanism for determining authority, relevance, and authoritativeness. And so, this Comment has excavated some support for believing that this structure is founded on an anxiety of authority. And it is possible, perhaps likely, that an intricate and complex system of determining and weighing textual (and extratextual) authority is a necessary by-product of an American legal system that is plagued by concerns about authority, in the many senses of the word.

This is, as patriots are fond of saying, a nation of laws, one that respects the "rule of law." Thus, legal texts are the ultimate authority.

1343 (praising the students at The University of Chicago Law School for challenging The Bluebook).

${ }^{119}$ See, e.g., Dickerson, supra note 4, at 88-89 ("[E]ven the four schools that produce the Bluebook [sic] do not always agree on style and do not always follow its rules.").

${ }^{120}$ Jan M. Levine, ALWD Biennial Conference Plenary Address 2. (July 1997) (on file with author).

${ }^{121}$ ALWD MANUAL, supra note 28 (emphasis added). Moreover, Professor Dickerson, the lead author of the ALWD Citation Manual, is an expert on citation not through editorship of The Bluebook (she attended Vanderbilt University School of Law), but apparently through professional study (as Director of Research and Writing at Stetson University College of Law). Dickerson, supra note 4, at 53 n.aa. 
Their status as primary might well lend itself to a generalized anxiety about the authoritative texts themselves. But we have seen more than simply a generalized anxiety; we have seen specific anxieties about when to cite (virtually always), how much to cite (more), and whom to cite (the expert). These various anxieties of authority all serve to ensure that propositions in legal texts are backed up by authority sufficient to make them unremarkable. Each step in an argument, except, perhaps, the ultimate, is well-grounded in what has come before, and the contribution of that ultimate step can therefore be seen as an incremental one. Thus, conventions of legal citation contour legal academics to the processes of the common law-the slow, deliberate development of legal doctrine through the accretion of precedent. The conventions of citation embodied in The Bluebook are not, then, anomalies. Rather, their resolute caution might well be a function of a legal system that is fundamentally conservative, requiring that the legal actor is always aware of the influence of her powerful predecessors. From this perspective, the anxiety of authority in legal analysis is an outgrowth of the anxiety of influence, molded by the shape of legal culture. The anxiety created by the influence of predecessors obtains here, as elsewhere. It is the response to that anxiety that differs, for where the poet must disavow such influence, the legal writer must embrace it. 